\title{
Teaching Integrated Pest Management Using the Learn-by-Doing Philosophy
}

Robert P. Rice, Jr.

ADDITIONAL INDEX WORDS. problem-based learning, integrated pest management, IPM

Summary. C alifornia Polytechnic State U niversity's (C al Poly) learn-by-doing philosophy permeates all areas of the environmental horticultural science curriculum by combining an emphasis on the science of horticulture in lecture sessions and the opportunity to engage in activities similar to those used by industry in the lab activities integral in all courses. The course, D isease and Pest Control Systems in O rnamental Plants (E H S 427), has taken this philosophy a step further by using problem-based learning and allowing students to function as pest control advisors and qualified applicators in the class. This approach has resulted in greatly increased student understanding of pest control, improved student morale, and increased interest in integrated pest management careers and research projects.

A s an originator of the learn-by-doing philosophy of university education, Cal Poly's agriculture programs have long combined a strong emphasis on the science of agriculture with hands-on laboratories and production opportunities. In the Environmental $\mathrm{H}$ orticultural Science D epartment (formerly O rnamental $\mathrm{H}$ orticulture), students operate a nursery, floral and foliage production greenhouses, shadehouses, field production areas, a retail flower shop and nursery as well as landscape facilities including an arboretum, a U.S. G olf Association green and other landscaped areas. A part of the operation of these facilities is the control of pests including weeds, arthropods, diseases and vertebrate pests. The course, D isease and Pest Control Systems in O rnamental Plants (E H S 427), is a capstone course that is the primary vehicle for teaching integrated pest management technology. This course uses problem-based learning (PBL) as the primary mode of instruction.

Problem-based learning (PBL) is a teaching method that confronts students with real-life problems and then challenges them to use available resources to solve these problems (J ones et al., 1997). This emphasis on problem solving is a departure from the usual lecture and memorization teaching methodology used in universities, and more closely approximates the type of activities which college graduates perform in the workplace.

Environmental H orticultural Science D epartment, California Polytechnic State U niversity, San L uis O bispo, CA 93407.

The cost of publishing this paper was defrayed in part by payment of page charges. U nder postal regulations, this paper therefore must be hereby marked advertisement solely to indicate this fact. 
In problem-based learning, the instructor assumes the role of a learning facilitator rather than a packager and deliverer of information as in the lecture mode of instruction. Typically, the instructor provides detailed information on the problem-solving process and methodology to access the information necessary to solve problems (Brooks and Brooks, 1993). Students are given problems to solve that will require them to use resources and follow procedures that lead them to attain the class objectives. The emphasis, thus, becomes the process of learning rather than the quantity of information memorized.

Some of the advantages of PBL include the emphasison problem solving methodology, increased student interest and involvement in the class (Brooks and Brooks, 1993); better retention and recall of information learned (Bridgesand $\mathrm{H}$ allinger, 1992); acquisition of skills directly applicable to the workplace including social and interpersonal skills; and compatibility with distance learning. Since, in most agricultural disciplines, graduatesspend alarge proportion of their timesolving problems, PBL hones their skills and narrows the gap between school and workplace (Blumenfeld et al., 1991). As a part of problem solving, students also learn the research and synthesis skills required in the workplace. Though theemphasisisnot on memorization of information, through usage and research, students do acquire significant quantities of information. This information is more likely to be accessible in the future compared to information memorized to pass a test. Since PBL allows students to meet class objectives without regular attendance at scheduled lectures (which don't exist in a pure PBL format), it is adaptable to distance learning formats through the use of chat rooms, e-mail, teleconferencing, and other technologies which permit the instructor to interact with students regardless of distance.

D isadvantages also are associated with the PBL mode of instruction, including greatly increased faculty organizational and office time, possibly lower scoreson standardized fact-based tests, and more difficulty in using PBL in lower level classes where students' research skills are less developed and they lack a knowledge base in the subject matter. Instructors often find that the time spent on organizing the class and providing materials needed by students to assist them in solving the problems presented to them is greater than that required to teach a lecture-based class. Additionally, students often require a great deal of individual attention to assist them in the process of problem solving especially because they have often not experienced this method of instruction previously. This problem can be partially overcome by the use of a class manual and/ or World Wide Web (Web) pagethat provides the information necessary to get them started on their projects. Of course, the writing and updating of the class manual and Web page is also time-consuming for the instructor. Since problem solving presupposes a certain amount of basic knowledge, PBL may be more applicable to upper division courses after students have learned basic horticultural information. Finally, students must realize that the expected learning outcomes from a PBL course are very different compared to those in a lecture course. Studentscannot expect to have learned as much factual information, though they will in the end be much better equipped to work in the discipline because they will have become facile in the acquisition and use of the information required in their discipline. Still, they may not do aswell on standardized, fact based tests used by, for example, state licensing agencies. Finally, some students do not like problem-based learning because the knowledge is no longer packaged and delivered to them but rather requires them to be involved actively in its acquisition, which requires self-motivation.

In some cases, the combination of PBL and more traditional modes of instruction such as lecture may be a way to overcome some of the disadvantages of a class taught purely with problem-based learning and, according to Gardner's theory of multiple intelligences (Gardner, 1991), will allow students who learn differently to benefit from different instructional modes. This combination of PBL, lecture, student class presentations and practical laboratory activities is used to teach pest management in the 400 level course, D isease and Pest C ontrol Systems in O rnamental Plants.

The objectives of this class are to teach students to identify pests, moni- tor populations, and to make commercially viablepest management decisions. They also are expected to be able to safely calculate, mix and apply pesticides or to use other pest management techniques, such as environmental controls and the use of biological control agents, and to evaluate outcomes. At the conclusion of the class, most students are able to pass state licensing exams with minimal additional study.

Class mechanics. The class meets $6 \mathrm{~h}$ per week with $3 \mathrm{~h}$ of laboratory and $3 \mathrm{~h}$ scheduled as lecture. About half of the lecture periods are used for lecture and half for student presentations of their pest management problems. L ectures are given on pesticide laws and regulations, pesticide safety, pest control principles, and application technology. Students work in groups of three to five (four seems to be optimum) to solve six pest management problems per group during the 10week quarter. A variety of problems arechosen based on what problemsare occurring at the 16-acre (6.5-ha) Environmental $\mathrm{H}$ orticulture Teaching $U$ nit, and the need to give students a variety of insect, disease, and weed control experiences. Students also are given the opportunity to use a variety of spray equipment including a computerized turf sprayer, hydraulic sprayers, electrostatic sprayers, a cold fogger, granular applicators, drench equipment, proportioners, and others. Typically, a group will be assigned to solve a problem such as two-spotted spider mites (Tetranychus urticae Koch) in the rose ( $R$ osa $L$.) production greenhouse. The students are shown the problem and then must diagnose the causal agent, monitor populations, research the problem and all possible controls including biological, physical, chemical, etc. and then recommend a control using a State of California Pest Control Advisor recommendation form. The group writes a detailed paper covering their investigation and presents a 7-min synopsis to the class. Copies of the written papers are distributed to all groups who are responsible for following the problem and its resolution. D uring lab the following week the group applies their recommended control and evaluates results. The group then briefs the class on the results and gives suggestions for future action. The instructor uses student presentations for discussion points. 
To facilitatestudent problem solving, the students are provided with a detailed class handbook which contains a wide variety of information to get the students started on their research, a sprayer math auto-tutorial to aid them with their calculations, reserve materials including current pesticide labels, reference books, samples of previousreports and term notebook projects, a classW eb page (Rice, 2000) with links to many pest management sites, and pest monitoring equipment.

Students are evaluated by grades on the six projects, a class notebook that the students compile during the quarter and is used by them to take the open-notefinal exam, amultiplechoice exam over laws and regulations that is similar to the statelicensing exam, and peer evaluation of their performance in their groups.

\section{Conclusions}

After 15 quarters of teaching the class using the above methodology and comparing results to the same class taught in a lecture format, the following observations can be made:

- PBL has been much more difficult to use in larger classes. The optimum class size has been 16 students. The maximum accommodated has been 32 divided into two lab sections. L arge lecture sections create a huge burden on the instructor in grading and evaluation of weekly projects and too much time is spent on student presentations to the detriment of discussions and lecture in the lecture section. This problem could be partially overcome by some reorganization or by doing fewer classroom presentations.

- Students with poor social skills do not perform aswell dueto thegroup format but report that they improve their ability to work in groups by the end of the class.

- Student satisfaction with the class has increased since switching to PBL. Students report that the class is relevant and has helped them to integrate information they have learned in earlier classes.

- Studentgradeshaveimproved; however, their performance on a standard multiple choice final exam requiring detailed knowledge of pesticides has declined slightly.

- Student problem solving skills as evidenced by their ability to make pest control recommendationshave improved dramatically.

- In student evaluations of the class, $50 \%$ of students report that they learned much more than in other Cal Poly classes, $40 \%$ learned more, and $9 \%$ learned about the same. $\mathrm{N}$ o student has reported that they learned less than in other Cal Poly classes.

In summary, PBL has been a very effective method for the teaching of integrated pest management when combined with lecture, student presentations, and laboratories which allow students to perform and evaluate pest management recommendations.

\section{Literature cited}

Blumenfeld, P.C., E. Soloway, R.W. M arx, J.S. Krajcik, M. Guzdial, and A. Palincsar. 1991. M otivating project-based learning: Sustaining the doing, supporting thelearning. Educ. Psychol. 26:369-398.

Bridges, E.M. and P. H allinger. 1992. Problem-based learning for administrators. Clearinghouse on Educational $M$ anagement, U niv. Ore., Eugene.

Brooks, J.G. and M.G. Brooks. 1993. In search of understanding: The case for constructivist classrooms. Assn. Supervision and Curriculum D ev., Alex., Va.

Gardner, H . 1991. The unschooled mind: H ow children think and how schoolsshould teach. Basic Books, N ew York.

Jones, B.F., C.M. Rasmussen, and M.C. M offitt. 1997. Real-life problem solving: A collaborative approach to interdisciplinary learning. Amer. Psychol. Assn., Wash. D.C.

Rice, R.P. 2000. OH 427 D isease and pest control systems for ornamental plants. 19 Jan. 2000. «ttp:// www.calpoly.edu/ -envhort/ oh427.html>. 